\title{
Effect of Staff Number on the Bacteria Contamination in Operating Rooms with Temperature Controlled Airflow Ventilation and Turbulent Mixing Ventilation
}

\author{
Cong Wang, Parastoo Sadeghian, Sasan Sadrizadeh \\ KTH Royal Institute of Technology, Stockholm, Sweden
}

\begin{abstract}
This study numerically investigated the effect of staff number on the airborne bacteria contamination in two operating rooms (ORs) equipped respectively with conventional turbulent mixing and temperaturecontrolled airflow $\left(\mathrm{T}_{\mathrm{c}} \mathrm{AF}\right)$ ventilation. Four pre-defined cases with 3, 5, 7, and 9 surgical staff surrounding the operating table were simulated. The contamination level steadily rises as more persons were added in the turbulent mixing ventilation. The $\mathrm{T}_{\mathrm{c}} \mathrm{AF}$ ventilation, however, is less sensitive to the number of persons in the OR and maintains a sufficiently low level of contamination in all cases. The mixing ventilation examined in this study is not recommended for infection-prone surgeries if more than 4-5 personnel should be present in the OR. In contrast, the OR with $\mathrm{T}_{\mathrm{c}} \mathrm{AF}$ ventilation can accommodate at least 9 surgical professionals without comprising the ultraclean environment at the surgical site. Comparisons with the analytical estimation based on the perfect dilution model also indicate that $\mathrm{T}_{\mathrm{c}} \mathrm{AF}$ uses airflow more efficiently than the mixing ventilation.
\end{abstract}

\section{Introduction}

Bacteria transported in the operating room (OR) air may enter the incision site during surgical procedures and cause surgical site infections (SSIs). SSIs remain one of the most challenging postoperative complications of health care, which contribute substantially to the increased morbidity, prolonged hospitalization, and repeat surgeries (de Lissovoy et al. 2009). Despite the complexity in the incidence of SSIs, it has been widely accepted that air with a low count of viable bacteria is one of the most crucial factors in minimizing the risk SSIs. In the landmark study of 8000 total hip and knee arthroplasties at 19 hospitals, Lidwell et al. (1982) found a significantly positive correlation between the count of viable bacteria in the air and the rate of deep infections. In a recent randomized, controlled study of infections during prosthesis implantations, Darouiche et al. (2017) confirmed that bacterial contamination of air at the incision site was a significant source of implant infections and reducing them also reduced the risk of infections.

The surgical staff have been considered as the primary source of bacteria in the OR air (Hoffman et al. 2002). The majority of the bacteria dispersed in the OR air are carried on squamae, skin scales, or particles, shed from human body (Dankert, Zijlstra, and Lubberding 1979; Lidwell 1988; Woods et al. 1986). A person releases about 10 million particles per day during moderate physical activity, approximately $5-10 \%$ of which carry bacteria (Hambraeus 1988). These bacteria-carrying particles (BCPs) range 5-20 $\mu \mathrm{m}$ in size (Noble, Lidwell, and Kingston 1963), with an average aerodynamic diameter of $12 \mu \mathrm{m}$ (Friberg et al. 1996; Noble 1975; Whyte 1986). Many previous research works including both experimental and numerical studies have indicated that the level of airborne BCPs is positively related to the number of persons present in the OR (Andersson et al. 2012; Darouiche et al. 2017; Sadrizadeh et al. 2014; Stocks et al. 2010, 2011). It is therefore straightforward to recommend a minimized surgical team to reduce the risk of infections. However, it can be difficult to reduce the staff number in certain surgical procedures. The orthopaedic OR personnel, for instance, consist typically of 5-9 medical professionals, with a median number of 7 (Alsved et al. 2018).

The prevention of SSIs has received considerable attention and various measures have been suggested. The interventions to reduce the infection risk include timely administration of appropriate preoperative antibiotics and a variety of preventive measures aiming at limiting the airborne bacteria concentration in the surgical environment. The rapid emergence of antibiotic-resistant bacteria nowadays has made the role of OR ventilation increasingly important. The ventilation system in the OR delivers filtered and particle-free air and attempts to maintain a hygienic and comfortable environment for both the patient and the OR personnel.

Operating rooms used to be designed with conventional turbulent mixing ventilation. The principle of mixing ventilation is to dilute the airborne contamination in the OR using supply air. Specifically, filtered air is discharged into the room through ceiling- or wallmounted diffusers and the incoming clean air is mixed with contaminated air in the OR. In this way, when a sufficient amount of air is supplied, the airborne BCPs concentration can be reduced to a level that is associated with an acceptable risk of infections. Concerns about the efficiency of mixing ventilation have been raised, since the ventilation airflow with the dilution principle attempts to purify the environment of the entire OR including regions that are remote from the incision site. A more efficient strategy may be to focus on controlling 
the airborne environment surrounding the incision site. A new air distribution scheme, known as temperaturecontrolled airflow $\left(\mathrm{T}_{\mathrm{c}} \mathrm{AF}\right)$, has recently been developed and evaluated (Alsved et al. 2018; Wang, Holmberg, and Sadrizadeh 2018). In a $T_{c} A F$ ventilated operating room, clean air is supplied at two different temperature levels. The cooled air is discharged to the surgical zone from central diffusers installed above the operating table, whereas the slightly warmer air is dispersed into the OR periphery through several ceiling-mounted surrounding diffusers. The supply temperatures are controlled to establish a $1.5-3.0^{\circ} \mathrm{C}$ temperature gradient between the central supply air and the OR ambient. Due to the buoyancy effect, the central supply air is accelerated by gravity and falls down to the surgical critical zone with a strong momentum to wash BCPs away from the patient and sterile instrument. The surrounding supply air further dilutes the airborne BCPs contamination in the periphery of the OR.

The surgical personnel have a two-fold effect on the contaminant distribution in an OR. First, the persons in the OR serve as an obstruction and heat source that alter the airflow. Second, the surgical staff contribute to the source of BCPs. Sadrizadeh et al. (2014) numerically investigated the influence of staff number on the BCPs distribution in a conventionally ventilated OR. A growing trend in airborne BCPs concentration was clearly observed as the number of personnel increases and the authors concluded that infection-prone procedures should not be performed in the examined OR with more than six personnel.

To the best of our knowledge, however, no literature has indicated whether the increased number of personnel leads to rising BCPs concentration in a $\mathrm{T}_{\mathrm{c}} \mathrm{AF}$ ventilated OR. Thus, this study aims to evaluate the performance of $\mathrm{T}_{\mathrm{c}} \mathrm{AF}$ under the conditions of different staff number. Computational Fluid Dynamics (CFD) is employed to simulate pre-defined cases with different number of OR personnel. For the purpose of comparisons, the same cases are also simulated for the OR with mixing ventilation and results are compared.

\section{Methodology}

\section{Physical model}

Two operating rooms in Helsingborg General Hospital (Helsingborg, Sweden) were chosen as the physical model for this study. The two ORs had identical dimensions $6.4 \mathrm{~m} \times 6.3 \mathrm{~m} \times 3 \mathrm{~m}$ (Length $\times$ Width $\times$ Height) but were equipped with mixing and $\mathrm{T}_{\mathrm{c}} \mathrm{AF}$ ventilation respectively. The operating tables of size 2.0 $\mathrm{m}$ (length) $\times 0.6 \mathrm{~m}$ (width) $\times 0.9 \mathrm{~m}$ (height) were located in the centre of the ORs. Two surgical lamps with a diameter of $0.6 \mathrm{~m}$ were positioned at a height of $1.8 \mathrm{~m}$ above the floor in either OR. The lamps were tilted at an angle illuminating the likely incision site. Two pieces of medical equipment, one with size $0.5 \mathrm{~m} \times 0.3 \mathrm{~m} \times 1.2 \mathrm{~m}$ (height) and the other $0.5 \mathrm{~m} \times 0.3 \mathrm{~m} \times 1.6 \mathrm{~m}$ (height), were also placed in the ORs. Four different cases with 3 , 5,7 , and 9 surgical staff surrounding the operating table respectively, were investigated. The patient was not

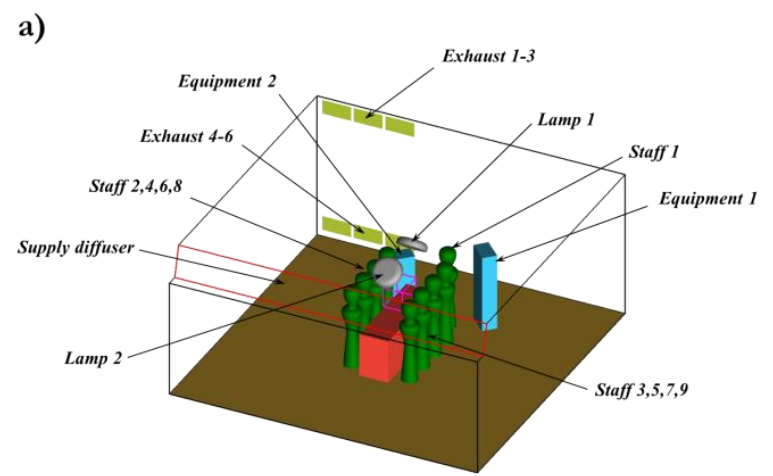

b)

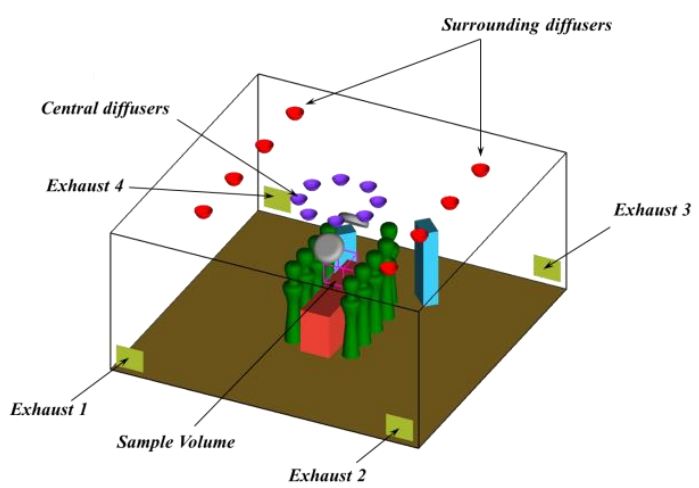

Figure 1: Overview of the ORs and internal constellation (only the case with 9 persons was shown): a) OR with turbulent mixing ventilation; b) OR with temperature-controlled airflow $\left(T_{c} A F\right)$ ventilation.

included in the analysis, as the purpose of the study was to investigate the influence of OR personnel on the risk of patient infections. Figure 1 presents the overview of the OR and the internal constellation of the persons and furnishings. Due to the limited space, only the case with 9 persons was shown.

In the first OR with conventional turbulent mixing ventilation (Figure 1-a), air was supplied from the 0.64 $\mathrm{m} \times 6.4 \mathrm{~m}$ diffuser located on the top of one sidewall. Room air was extracted through six $0.6 \mathrm{~m} \times 0.3 \mathrm{~m}$ return vents on the opposite sidewall. The supply airflow rate was $3200 \mathrm{~m}^{3} / \mathrm{h}$, corresponding to 26 air changes per hour $(\mathrm{ACH})$. The second $\mathrm{OR}$ was ventilated by $\mathrm{T}_{\mathrm{c}} \mathrm{AF}$ at an airflow rate of $5600 \mathrm{~m}^{3} / \mathrm{h}$, or $46 \mathrm{ACH}$ (Figure 1-b). The cooler air discharged into the OR through eight central diffusers evenly mounted on the ceiling, whereas slightly warmer air was released into the OR periphery through eight additional ceiling-mounted diffusers in parallel arrangement. The airflow rate was evenly distributed between the 16 diffusers. Air exits the OR through four $0.56 \mathrm{~m} \times 0.56 \mathrm{~m}$ low-level vents near the corner of the OR.

\section{Numerical modelling}

Each of the surgical staff contributed to a heat load of $100 \mathrm{~W}$ (Chow, Lin, and Bai 2006). A heat flux of 300 $\mathrm{W} / \mathrm{m}^{2}$ was released from the exposed surfaces of the medical instrument. The surgical lamps emitted a heat flux of $320 \mathrm{~W} / \mathrm{m}^{2}$ from their downward-pointing faces. Each person present in the OR was assumed to shed BCPs at a rate of 5 Colony Forming Unit (CFU)/s (SIS- 
TS 39 2015). The particle size was considered $12 \mu \mathrm{m}$, which is the average size of BCPs causing infections. The heat and contaminant sources were assumed uniform at their emitting surfaces.

The supply temperature of the mixing ventilation was kept at $20^{\circ} \mathrm{C}$. The temperature of the central supply air in the $\mathrm{T}_{\mathrm{c}} \mathrm{AF}$ ventilation was set to $18{ }^{\circ} \mathrm{C}$. A Fluent SCHEME script was written to control the supply temperature at the surrounding diffusers, which replicates the control strategy of the $\mathrm{T}_{\mathrm{c}} \mathrm{AF}$ ventilation. The surrounding supply temperature was adjusted in such a way that the resultant OR ambient temperature measured at two sidewalls at $1.2 \mathrm{~m}$ above the floor was $1.5^{\circ} \mathrm{C}$ higher than the central supply air (i.e. $19.5^{\circ} \mathrm{C}$ ).

The airflow field and particle transport were simulated using the commercial CFD code ANSYS Fluent 18.2. The Realizable $k-\varepsilon$ model with Enhanced Wall Treatment (EWT) was employed to model the turbulent airflow. The Lagrangian Particle Tracking (LPT) approach with Discrete Random Walk (DRW) was adopted to resolve particle trajectories. Unstructured tetrahedral meshes were used in the simulation. After gird convergence studies, depending on the cases, meshes with 4.5-4.8 million cells were found to give grid independent solutions. Thermal radiation was not modelled and thus all heat loads were taken as convective. Due to the large ventilation rate, this simplification will not significantly affect the results and conclusions. The validation of numerical models and details of boundary conditions can be found in our previous studies (e.g. Sadrizadeh et al. 2014; Wang, Holmberg and Sadrizadeh 2018).

Both the airborne BCPs contamination $\left(\mathrm{CFU} / \mathrm{m}^{3}\right)$ and the surface BCPs contamination $\left(\mathrm{CFU} / \mathrm{m}^{2} \mathrm{~h}\right)$ were calculated, respectively corresponding to the active air sampling (AAS) and passive air sampling (PAS). Specifically, the airborne BCPs concentration was evaluated in the $0.4 \mathrm{~m}$ $\times 0.6 \mathrm{~m} \times 0.4 \mathrm{~m}$ (height) sampling volume at the operating table, as shown in Figure 1. The BCPs sedimentation rate on the entire upper surface of the operating tables was taken as the surface contamination.

An analytical formula, as given in $\mathrm{Eq} 1$. , is recommended by certain standards and design guidelines to estimate the contamination level in ORs (e.g. SIS-TS 39 2015). Given the ventilation rate and the contaminant source strength per person, the airborne BCPs concentration is a linear function of the number of persons present in the OR

$$
c=\frac{n_{p} \times q_{s}}{Q}
$$

where $c$ is the airborne BCPs concentration, $n_{p}$ is the number of OR personnel, $q_{s}$ is the source strength per person, and $Q$ is the ventilation airflow rate. Caution is needed when interoperating the predictions by Eq.1, as it assumes perfect dilution with fully mixed airflow in the OR, which is never achieved in a real OR. In this study, we also compared the simulated airborne BCPs concentration with the estimation by Eq. 1 .

\section{Results and discussions}

The ventilation performance in the two existing ORs is evaluated at the designed operating airflow rate of each ventilation system. The primary objective of the study is to investigate how increasing staff number influences the $\mathrm{BCPs}$ contamination under each ventilation. The analysis of the two ventilation systems under identical airflow rates can be found in our previous works (e.g. Wang, Holmberg, and Sadrizadeh 2018).

Upon convergence, the surrounding supply temperature of the $\mathrm{T}_{\mathrm{c}} \mathrm{AF}$ ventilation stabilised. Depending on the cases, this temperature varied from $19.2^{\circ} \mathrm{C}$ to $20.2^{\circ} \mathrm{C}$. As more staff were added in the OR, the supply temperature at the surrounding diffusers decreased.

Figure 2 and Figure 3 present the velocity vectors at the vertical plane passing the centre of the operating table for the mixing and $T_{c} A F$ ventilation respectively (see Appendix). As seen in Figure 2, in the mixing ventilation the airflow is weak in the region remote from the supply diffuser and no clear flow patterns can be identified. In contrast, despite the obstruction imposed by the lamps, down-flow streams in the surgical zone can be clearly seen in Figure 3 presenting the $\mathrm{T}_{\mathrm{c}} \mathrm{AF}$ ventilation. The downward airflow is expected to efficiently remove the BCPs from the surgical zone. The air speed is significantly reduced outside the surgical zone, which indicates a diluting airflow pattern in the periphery of the OR. Figure 2 and 3 demonstrates that both ventilation systems function as they are designed. The OR personnel alters the airflow in the mixing ventilation, as the exhibited airflow shows slight difference with the increased number of persons present. However, the difference between the four cases in the $T_{c} A F$ ventilation is nearly negligible. Consistent with previous studies (Wang, Sadrizadeh, and Holmberg 2018a; Wang, Sadrizadeh, and Holmberg 2018b), this finding adds to the evidence that $\mathrm{T}_{\mathrm{c}} \mathrm{AF}$ is less sensitive to obstructions and heat loads in the surgical zone.

The simulated airborne BCPs concentration at the operating table and the predicted BCPs concentration using Eq. 1 are plotted against staff number in Figure 4, whereas Figure 5 presents the simulated surface BCPs concentration.

Not surprisingly, the contamination level steadily rises as the staff number increases in the OR with mixing ventilation. The surface contamination increases linearly, whereas the growth rate of the airborne contamination shows slight fluctuations between cases. This can be ascribed to the fact that the presence of persons slightly alters the local airflow filed and that the relative positioning of the persons to the sampling volume also has an effect on the results.

In contrast, the $\mathrm{T}_{\mathrm{c}} \mathrm{AF}$ ventilation maintains a sufficently low level of contamination regardless of the number of persons in the OR. The airborne BCPs concentration slightly fluctuates between $0.3-1.0 \mathrm{CFU} / \mathrm{m}^{3}$ at the operating table and surface contamination grows very slowly as the staff number increases. The highest level of surface contamination is found to be $60 \mathrm{CFU} / \mathrm{m}^{2} \cdot \mathrm{h}$ 
a)

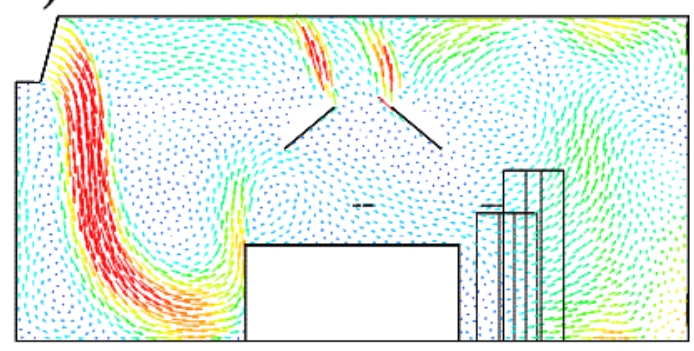

c)

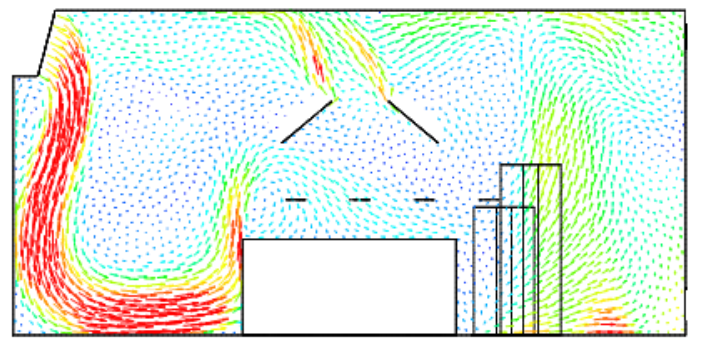

b)

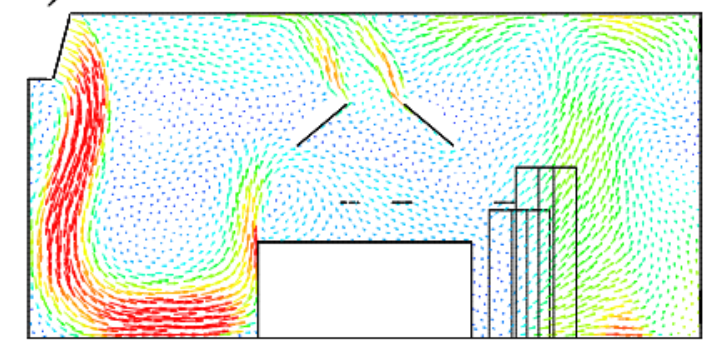

d)

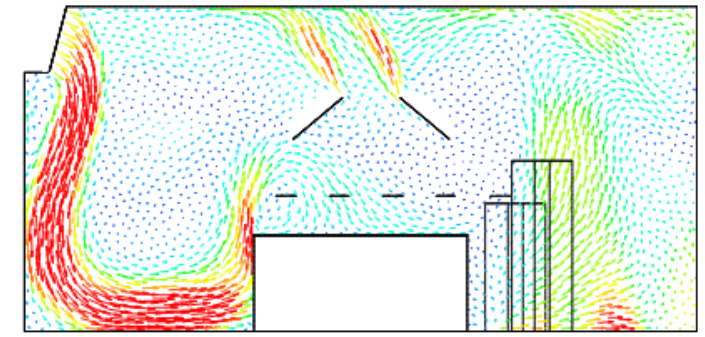

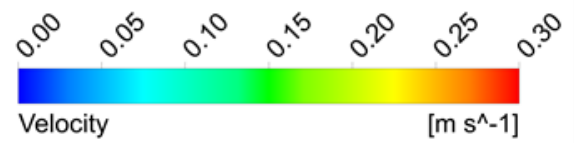

Figure 2: Velocity vector plot at the centre-plane of the operating table in the turbulent mixing ventilation: a) case with 3 persons; b) case with 5 persons; c) case with 7 persons; d) case with 9 persons.

a)

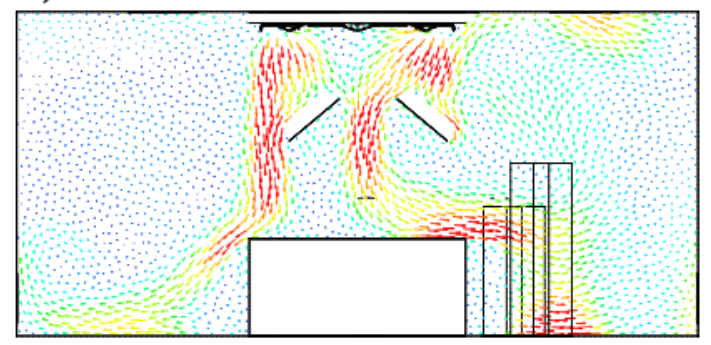

c)

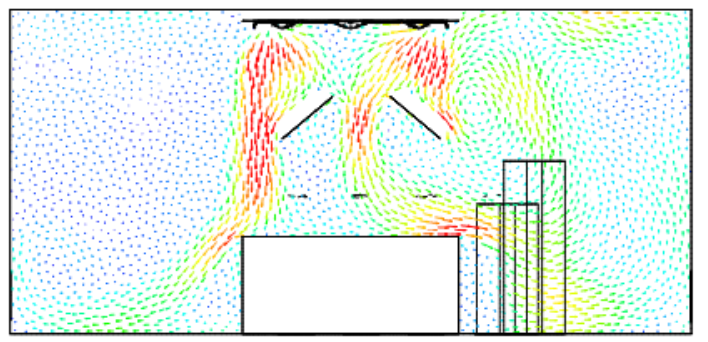

b)

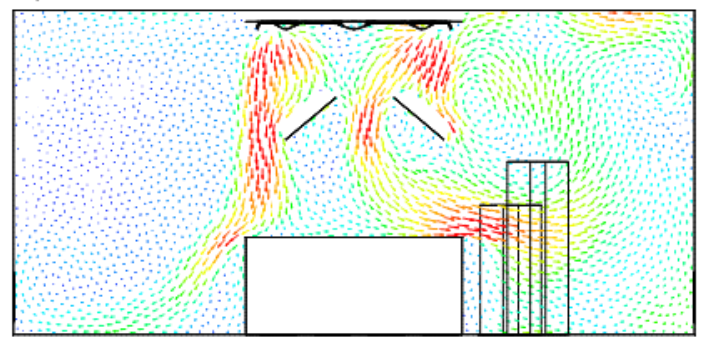

d)

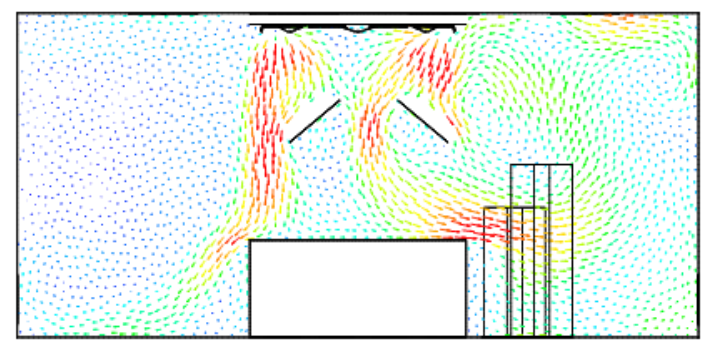

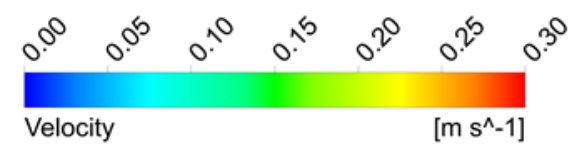

Figure 3: Velocity vector plot at the centre-plane of the operating table in the temperature-controlled airflow $\left(T_{c} A F\right)$ ventilation: a) case with 3 persons; b) case with 5 persons; c) case with 7 persons; d) case with 9 persons. 
in the case of 9 persons, whereas the maximum airborne BCPs concentration is achieved in the case of 7 persons. This inconsistency between airborne and surface contamination is also attributable to the local airflow field and the positioning of the persons.

Eq. 1 overpredicts the airborne contamination in all cases for both mixing and $\mathrm{T}_{\mathrm{c}} \mathrm{AF}$ ventilation, which reflects that the airflow is not fully mixed even in the mixing ventilation. It is noteworthy that simulated airborne BCPs concentration in the mixing ventilation converges to the analytical estimation as more persons are present in the OR. However, the departure of the contamination estimation by Eq. 1 from the simulation in the $T_{c} A F$ ventilated $O R$ is expanded as the staff number increases. Despite the fact that $\mathrm{T}_{\mathrm{c}} \mathrm{AF}$ operates at a higher airflow rate, it can be concluded that $\mathrm{T}_{\mathrm{c}} \mathrm{AF}$ uses airflow more efficiently than the mixing ventilation that is based largely on the dilution principle.

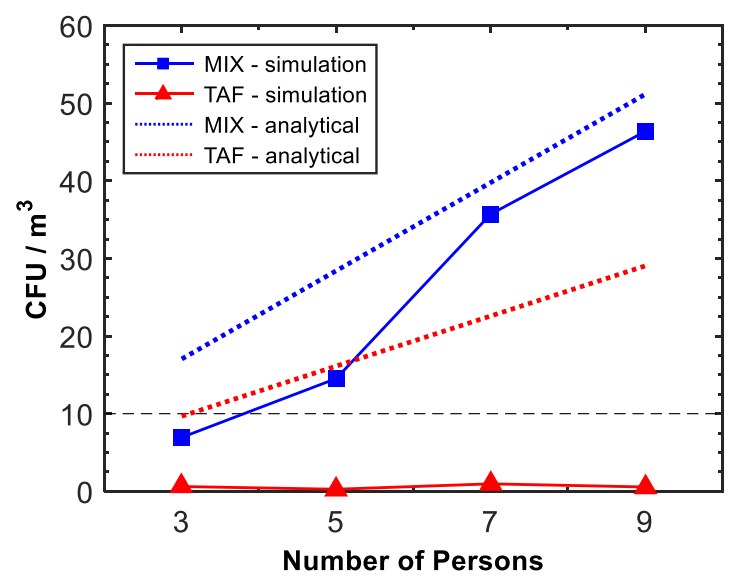

Figure 4: Simulated airborne BCPs contamination and comparison with the estimation by Eq.1 (horizontal dash line indicates the recommended limit for an ultraclean environment).

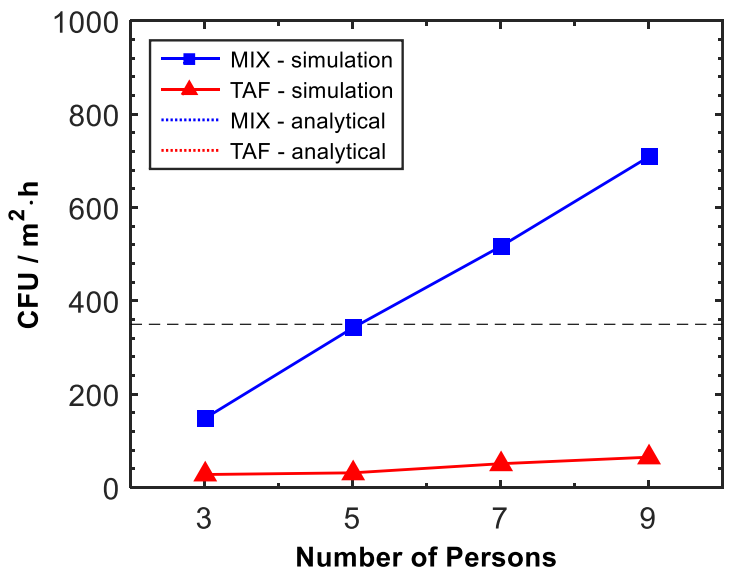

Figure 5: Simulated surface BCPs contamination (horizontal dash line indicates the recommended limit for an ultraclean environment).
Ultraclean air is required for infection-prone procedures, such as orthopaedic and implants surgeries, to minimize the risk of SSIs. The internationally accepted definition of ultraclean air is airborne BCPs concentration < $10 \mathrm{CFU} / \mathrm{m}^{3}$ (Whyte 1988). For the surface BCPs concentration, Friberge et al. (1999) proposed the corresponding limit of $350 \mathrm{CFU} / \mathrm{m}^{2} \cdot \mathrm{h}$. The two limit values are denoted by the horizontal dash lines in Figure 4 and 5. Based on the simulation results, no more than 45 personnel should be present in the OR with mixing ventilation. However, the $\mathrm{T}_{\mathrm{c}} \mathrm{AF}$ ventilation is capable of maintaining an ultraclean environment at the surgical site even in the case of 9 persons surrounding the operating table.

Our study has limitations. Many design variants exist for OR ventialtion and OR layouts also vary from surgery to surgery and from hospital to hospital. This may limit the generalizability of our findings. Furthermore, we did not evaluate the ventilation effectiveness in the ORs. In future studies, we will look into whether indoor air quality indicators, such as air exchange efficiency and contaminant removal effectiveness, are suitable for use in designing and commissioning OR ventilation systems.

\section{Conclusion}

This paper simulated the airflow field and bacteriacarrying particles (BCPs) distribution in operating rooms using Computation Fluid Dynamics (CFD) and Lagrangian Particle Tracking (LPT). The effect of staff number on the airborne BCPs concentration and deposition was investigated in operating rooms with conventional turbulent mixing ventilation and a newly developed ventilation strategy - temperature-controlled $\left(\mathrm{T}_{\mathrm{c}} \mathrm{AF}\right)$ airflow. Four cases were pre-defined with 3, 5, 7, and 9 surgical staff surrounding the operating table. The contamination level steadily rises as more personnel are added in the OR with mixing ventilation. The $\mathrm{T}_{\mathrm{c}} \mathrm{AF}$ ventilation, however, maintains a sufficiently low level of contamination regardless of the number of persons in the OR. The OR with conventional mixing ventilation examined in this study is not recommended for infection-prone surgeries if more than 4-5 personnel are needed to be present in the OR. In contrast, the OR with $\mathrm{T}_{\mathrm{c}} \mathrm{AF}$ ventilation can accommodate at least 9 surgical professionals without comprising the ultraclean environment at the surgical site. The simulation results were compared with the analytical estimation based on the perfect dilution model. The comparisons demonstrate that $\mathrm{T}_{\mathrm{c}} \mathrm{AF}$ uses airflow more efficiently than mixing ventilation based on the dilution principle.

The present study has limitations. The simulation was based on the specific designs of the turbulent mixing ventilation and $\mathrm{T}_{\mathrm{c}} \mathrm{AF}$. There exist many other design variants of both ventilation strategies. In addition, only particles of one size were simulated. Literature has shown that particles of different diameters behave differently in the air. Comprehensive research is needed in future work to provide deeper insight into the contaminant transport and distribution in operating rooms. 


\section{Acknowledgement}

The Swedish Research Council Formas provided the financial support for this study.

\section{References}

Alsved, M., Civilis, A., Ekolind, P., Tammelin, A., Andersson, A. E., Jakobsson, J., ... Löndahl, J. (2018). Temperature-controlled airflow ventilation in operating rooms compared with laminar airflow and turbulent mixed airflow. Journal of Hospital Infection, 98(2), 181-190.

Andersson, A. E., Bergh, I., Karlsson, J., Eriksson, B. I., \& Nilsson, K. (2012). Traffic flow in the operating room: An explorative and descriptive study on air quality during orthopedic trauma implant surgery. American Journal of Infection Control, 40(8), 750755.

Badia, J. M., Casey, A. L., Petrosillo, N., Hudson, P. M., Mitchell, S. A., \& Crosby, C. (2017). Impact of surgical site infection on healthcare costs and patient outcomes: a systematic review in six European countries. Journal of Hospital Infection, 96(1), 1-15.

Chow, T. T., Lin, Z., \& Bai, W. (2006). The Integrated Effect of Medical Lamp Position and Diffuser Discharge Velocity on Ultra-clean Ventilation Performance in an Operating Theatre. Indoor and Built Environment, 15(4), 315-331.

Dankert, J., Zijlstra, J. B., \& Lubberding, H. (1979). A garment for use in the operating theatre: the effect upon bacterial shedding. Journal of Hygiene, 82(01), $7-14$.

Darouiche, R. O., Green, D. M., Harrington, M. A., Ehni, B. L., Kougias, P., Bechara, C. F., \& O’Connor, D. P. (2017). Association of Airborne Microorganisms in the Operating Room With Implant Infections: A Randomized Controlled Trial. Infection Control \& Hospital Epidemiology, 38(01), 3-10.

de Lissovoy, G., Fraeman, K., Hutchins, V., Murphy, D., Song, D., \& Vaughn, B. B. (2009). Surgical site infection: Incidence and impact on hospital utilization and treatment costs. American Journal of Infection Control, 37(5), 387-397.

Friberg, B., Friberg, S., Burman, L. G., Lundholm, R., \& Ostensson, R. (1996). Inefficiency of upward displacement operating theatre ventilation. The Journal of Hospital Infection, 33(4), 263-272.

Hambraeus, A. (1988). Aerobiology in the operating room-a review. Journal of Hospital Infection, 11(Supplement A), 68-76.

Hoffman, P. N., Williams, J., Stacey, A., Bennett, A. M., Ridgway, G. L., Dobson, C., ... Humphreys, H. (2002). Microbiological commissioning and monitoring of operating theatre suites. Journal of Hospital Infection, 52(1), 1-28.
Lidwell, O. M. (1988). Air, antibiotics and sepsis in replacement joints (Medical Research Council). The Journal of Hospital Infection, 11 Suppl C, 18-40.

Lidwell, O. M., Lowbury, E. J., Whyte, W., Blowers, R., Stanley, S. J., \& Lowe, D. (1982). Effect of ultraclean air in operating rooms on deep sepsis in the joint after total hip or knee replacement: a randomised study. British Medical Journal (Clinical Research Ed.), 285(6334), 10-14.

Noble, W. C. (1975). Dispersal of skin microorganisms. British Journal of Dermatology, 93(4), 477-485.

Noble, W. C., Lidwell, O. M., \& Kingston, D. (1963). The size distribution of airborne particles carrying micro-organisms. The Journal of Hygiene, 61(4), 385-391.

Sadrizadeh, S., Tammelin, A., Ekolind, P., \& Holmberg, S. (2014). Influence of staff number and internal constellation on surgical site infection in an operating room. Particuology, 13, 42-51.

SIS-TS 39. (2015). Microbiological cleanliness in the operating room - Preventing airborne contamination - Guidance and fundamental requirements. Swedish Standard Institute.

Stocks, G. W., O’Connor, D. P., Self, S. D., Marcek, G. A., \& Thompson, B. L. (2011). Directed Air Flow to Reduce Airborne Particulate and Bacterial Contamination in the Surgical Field During Total Hip Arthroplasty. The Journal of Arthroplasty, 26(5), 771-776.

Stocks, G. W., Self, S. D., Thompson, B., Adame, X. A., \& O'Connor, D. P. (2010). Predicting bacterial populations based on airborne particulates: A study performed in nonlaminar flow operating rooms during joint arthroplasty surgery. American Journal of Infection Control, 38(3), 199-204.

Wang, C., Holmberg, S., \& Sadrizadeh, S. (2018). Numerical study of temperature-controlled airflow in comparison with turbulent mixing and laminar airflow for operating room ventilation. Building and Environment, 144, 45-56.

Wang C., Sadrizadeh, S., Holmberg, S. (2018a) Influence of the shape of surgical lamps on the airflow and particle distribution in operating rooms. Proceedings from Roomvent \& Ventilation 2018 Conference. Espoo (Finland) 2-5 June, 2018.

Wang C., Sadrizadeh, S., Holmberg, S. (2018b) Numerical Assessment of the Influence of Heat Loads on the Performance of TemperatureControlled Airflow in an Operating Room. Proceedings from AIVC 2018: 39th AIVC - 7th TightVent \& 5th venticool Conference Smart ventilation for buildings. Antibes Juan-Les-Pins (France), 18-19 September 2018.

Whyte, W. (1986). Sterility assurance and models for assessing airborne bacterial contamination. Journal 
of Parenteral Science and Technology: A Publication of the Parenteral Drug Association, 40(5), 188-197.

Whyte, W. (1988). The role of clothing and drapes in the operating room. Journal of Hospital Infection, 11, 217.
Woods, J. E., Braymen, D. T., Rasmussen, R. W., Reynolds, G. L., \& Montag, G. M. (1986). Ventilation Requirements in Hospital Operating Rooms - Part I: Control of Airborne Particles. ASHRAE Transactions, 92(2A), 396-426. 